University of Nebraska - Lincoln

DigitalCommons@University of Nebraska - Lincoln

USDA National Wildlife Research Center - Staff Publications
U.S. Department of Agriculture: Animal and Plant Health Inspection Service

2011

\title{
Evaluation of Fecal DNA Preservation Techniques and Effects of Sample Age and Diet on Genotyping Success
}

\author{
Michael Panasci \\ Texas Tech University, michael.panasci@ttu.edu \\ Warren B. Ballard \\ Texas Tech University, warren.ballard@ttu.edu \\ Stewart W. Breck \\ USDA/APHIS/WS National Wildlife Research Center, stewart.w.breck@aphis.usda.gov \\ David Rodriguez \\ Cornell University, daverdz5@gmail.com \\ Llewellyn D. Densmore III \\ Texas Tech University, lou.densmore@ttu.edu \\ See next page for additional authors
}

Follow this and additional works at: https://digitalcommons.unl.edu/icwdm_usdanwrc

Panasci, Michael; Ballard, Warren B.; Breck, Stewart W.; Rodriguez, David; Densmore, Llewellyn D. III; Wester, David B.; and Baker, Robert J., "Evaluation of Fecal DNA Preservation Techniques and Effects of Sample Age and Diet on Genotyping Success" (2011). USDA National Wildlife Research Center - Staff Publications. 1301.

https://digitalcommons.unl.edu/icwdm_usdanwrc/1301

This Article is brought to you for free and open access by the U.S. Department of Agriculture: Animal and Plant Health Inspection Service at DigitalCommons@University of Nebraska - Lincoln. It has been accepted for inclusion in USDA National Wildlife Research Center - Staff Publications by an authorized administrator of DigitalCommons@University of Nebraska - Lincoln. 


\section{Authors}

Michael Panasci, Warren B. Ballard, Stewart W. Breck, David Rodriguez, Llewellyn D. Densmore III, David B. Wester, and Robert J. Baker 


\title{
Evaluation of Fecal DNA Preservation Techniques and Effects of Sample Age and Diet on Genotyping Success
}

\author{
MICHAEL PANASCI, ${ }^{1}$ Department of Natural Resources Management, Texas Tech University, Box 42125, Lubbock, TX 79409-2125, USA \\ WARREN B. BALLARD, Department of Natural Resources Management, Texas Tech University, Box 42125, Lubbock, TX 79409-2125, USA \\ STEWART BRECK, USDA-Wildlife Services, National Wildlife Research Center, Fort Collins, CO 80521, USA \\ DAVID RODRIGUEZ, Department of Ecology and Evolutionary Biology, Cornell University, Ithaca, NY 14853, USA \\ LLEWELLYN D. DENSMORE III, Department of Biological Sciences, Texas Tech University, Box 43131, Lubbock, TX 79409, USA \\ DAVID B. WESTER, Department of Natural Resources Management, Texas Tech University, Box 42125, Lubbock, TX 79409-2125, USA \\ ROBERT J. BAKER, Department of Biological Sciences, Texas Tech University, Box 43131, Lubbock, TX 79409, USA
}

\begin{abstract}
Optimal collection and preservation protocols for fecal DNA genotyping are not firmly established. We evaluated 3 factors that influence microsatellite genotyping success of fecal DNA extracted from coyote (Canis latrans) scats: 1) age of scat, 2) preservative, and 3) diet content. We quantified genotyping success by comparing rates of allelic dropout, false alleles, and failed amplifications among consensus genotypes. We used a panel of 6 microsatellite loci to genotype 20 scat samples, each of which was subjected to 3 age ( 1 day, 5 days, and 10 days post-deposition) and 3 preservation (DET buffer, $95 \%$ ethanol [EtOH], and lysis buffer) treatments. Both sample age and storage buffer had a significant effect on success and reliability. Ethanol and DET buffer preserved fecal samples with similar efficiency, and both were superior to lysis buffer. Our analysis of DNA degradation rates revealed that samples collected as early as 5 days of age yielded DNA that was highly degraded relative to samples collected on day 1 . We tested the influence of dietary remains on microsatellite genotyping by using scat samples consisting predominantly of insect prey $(n=5)$, mammalian prey $(n=9)$, or the remains of juniper (Juniperus spp.) berries $(n=6)$ and compared $\mathrm{EtOH}$ and DET buffer preservation efficacy. We observed a significant interaction effect between storage buffer and diet for the probability of a false allele in a polymerase chain reaction (PCR), suggesting that the optimal preservation technique depended on the food remains comprising the scat. Scats comprised of juniper berry remains were more reliably genotyped when preserved in DET than EtOH. Mammalian preybased scats were more reliable when stored in $\mathrm{EtOH}$ than DET buffer. Insect-predominant scats were preserved in EtOH and DET buffer with similar efficiency. Although accurate and reliable results can be obtained from scats collected at $\geq 5$ days of age, we suggest sampling design to include collection of scats $<5$ days of age to minimize field and laboratory expenses. We suggest $\mathrm{EtOH}$ preservation for scats of obligate carnivores and of facultative carnivores with a diet consisting primarily of mammals. We suggest DET buffer preservation for animals with a diet consisting of plant-derived foods. Lysis buffer protocols that we employed should not be used for fecal DNA preservation. (c) 2011 The Wildlife Society.
\end{abstract}

KEY WORDS allelic dropout, amplification success, coyote, false allele, fecal preservation, genotyping errors, noninvasive sampling, sample age.

Recent advances in molecular techniques have facilitated a dramatic increase in the use of noninvasive genetic procedures in wildlife research and management. A common noninvasive sampling technique utilizes fecal samples from which DNA can be isolated from exfoliated epithelial cells of the defecating individual's intestinal wall (Albaugh et al. 1992). Both nuclear and mitochondrial DNA from feces is now routinely used in several research and management

Received: 31 March 2010; Accepted: 2 February 2011;

Published: 4 August 2011

${ }^{1}$ E-mail: michael.panasci@ttu.edu scenarios and has great potential for further application (Waits and Paetkau 2005).

However, a major limitation of noninvasive samples is that they typically yield low quantities of host DNA, and the DNA is often highly degraded (Taberlet et al. 1999) and contaminated with foreign genetic material (Broquet et al. 2007). These limitations often lead to erroneous genotypes, and special procedures that ensure accuracy of results are required (Waits and Paetkau 2005). Noninvasive genotyping errors are primarily due to allelic dropout (ADO), the stochastic amplification of only 1 of 2 alleles at a heterozygous locus in a positive polymerase chain reaction (PCR), and false 
alleles (FA) generated as PCR artifacts as a result of slippage early in the reaction (Broquet and Petit 2004) or from contaminant DNA (Taberlet et al. 1996, Gagneux et al. 1997).

Fecal DNA extraction and amplification success are influenced by both environmental factors (e.g., temperature, humidity, sun exposure; Farrell et al. 2000, Goossens et al. 2000, Lucchini et al. 2002, Nsubuga et al. 2004), of which scats are exposed to prior to collection, and by more controllable influences such as the time interval between scat deposition and collection, preservation method, storage duration, and various laboratory techniques (Wasser et al. 1997, Frantzen et al. 1998, Goossens et al. 2000). The diet of the organism also has been shown to influence genotyping success rates (Murphy et al. 2003). Many studies have attempted to improve fecal DNA genotyping techniques (e.g., Wasser et al. 1997, Frantzen et al. 1998, Morin et al. 2001, Murphy et al. 2002), but with so many variables influencing success, previous techniques developed with other species, or with similar species elsewhere, may be of limited applicability to new studies.

Several authors have evaluated the relative success of a number of preservation techniques (e.g., Wasser et al. 1997, Frantzen et al. 1998, Murphy et al. 2002) and have often reached different conclusions, even in cases in which similar preservatives were tested, suggesting that effectiveness varies among taxa, climatic conditions, and other variables. Unfortunately, studies have generally measured successful amplification based on the mere presence of PCR product (of the expected size on a gel) alone and did not follow up with a quantification of reliability based on error rates. Therefore, it remains to be established if the preservation methods that are efficient at producing PCR product produce reliable genotypes. There is no consensus on which preservation technique is optimal (Waits and Paetkau 2005), but ethanol (EtOH), DET buffer (20\% DMSO, $0.25 \mathrm{M}$ EDTA, $100 \mathrm{mM}$ Tris, $\mathrm{pH} 7.5$, and $\mathrm{NaCl}$ to saturation; Seutin et al. 1991), and silica desiccation have been suggested as preferable (Murphy et al. 2002, Frantzen et al. 1998, Wasser et al. 1997, respectively) and are among the most widely employed, whereas others, such as lysis buffer (Longmire et al. 1997), have been used extensively for preserving tissue but have yet to be thoroughly tested for fecal DNA preservation.

With few exceptions, of the studies attempting quantification of fecal DNA degradation rates prior to collection, uncertainty of sample age has required the ambiguous categorization of fresh versus old, which offers little beyond expected patterns; fresh samples contain a higher quantity and quality of DNA than old samples (Lucchini et al. 2002, Piggott 2004). Little is known, therefore, regarding degradation rates but evidence suggests that fecal DNA beyond 7-10 days of age typically fails to reliably yield microsatellite genotypes efficiently (Piggott 2004). Sampling strategy, survey protocols, and the time and cost of conducting surveys and lab work are all influenced by the degree of DNA degradation prior to sample collection and preservation.
Little is understood regarding dietary influences on genotyping success, but effects are believed to be the result of DNA extraction and PCR inhibitors found in some plant (i.e., polysaccharides; Kohn and Wayne 1997, Monteiro et al. 1997) and animal tissues (Murphy et al. 2003). A controlled diet study (Murphy et al. 2003) indicated that scat produced from captive brown bears (Ursus arctos) fed exclusively salmon (Salmo spp.) had significantly lower PCR amplification success rates relative to scats produced from bears on both a vegetarian and mammalian diet, suggesting high concentrations of PCR inhibitors in salmon tissues. Broquet et al. (2007), on the contrary, concluded from a review of noninvasive genetic literature that the diet of a species did not influence genotyping success.

Canids have been the focus of many fecal DNA studies (e.g., Lucchini et al. 2002, Adams et al. 2003, Cariappa et al. 2008), yet simultaneous evaluation of various storage buffers for canid fecal preservation is lacking and canid researchers have little empirical data to guide decisions on which preservation techniques and sampling strategies to employ. Our objective was to 1) evaluate the relative success and reliability of 3 preservation techniques: $95 \% \mathrm{EtOH}$, DET buffer, and lysis buffer (Longmire et al. 1997), 2) evaluate the effect of sample age (time from deposition to collection) on amplification success and reliability and thereby gauge rates of DNA degradation, and 3) ascertain the influence of particular dietary components on amplification success and reliability. Using the coyote (Canis latrans) as the study species, our goal was to provide sample and storage guidelines for researchers developing scat collection protocols for wild canid fecal DNA analyses.

\section{STUDY AREA}

We conducted research on federal, state, and private ranch lands in and adjacent to the Gila National Forest in southeastern Catron County, New Mexico, USA. The area was traversed with unpaved roads characterized by varying degrees of maintenance from state highway (e.g., Highway 163, which was approximately the eastern border of the study area) to 2 -track ranch roads. The primary land use of the area was domestic cattle grazing.

Potential coyote prey in the area primarily included Rocky Mountain elk (Cervus elaphus nelsoni), mule deer (Odocoileus hemionus), pronghorn (Antilocapra americana), jackrabbits (Lepus spp.), cottontail rabbits (Sylvilagus spp.), rodents (primarily represented by the families Sciuridae, Heteromyidae, and Muridae), and various insects. Dominant vegetation included ponderosa pine (Pinus ponderosa), juniper, piñon (Pinus cembroides), evergreen oaks (Quercus spp.), and a variety of grasses and forbs. Mean daily maximum and minimum temperatures during the sampling period of late June to mid-September 2007 were $26.4^{\circ} \mathrm{C}$ and $10.6^{\circ} \mathrm{C}$, respectively, and ranged from $32.8^{\circ} \mathrm{C}$ to $5^{\circ} \mathrm{C}$ (D. DuBois, New Mexico Climate Center, unpublished data). Rainfall during this period totaled $18.4 \mathrm{~cm}$ during 33 rain events, ranging from $0.01 \mathrm{~cm}$ to $1.33 \mathrm{~cm}$ per rain event (D. DuBois, unpublished data). Mean daily wind speeds averaged $4.51 \mathrm{~km} / \mathrm{hr}$, with maximum daily wind 
speeds ranging from $8.05 \mathrm{~km} / \mathrm{hr}$ to $45.06 \mathrm{~km} / \mathrm{hr}$ (D) DuBois, unpublished data).

\section{METHODS}

\section{Sample Collection and Preservation}

We conducted daily scat surveys from June to September 2007. We cleared existing scat from a $55-\mathrm{km}$ collection route (i.e., roads) and commenced daily surveys the following morning. Upon discovery of each new scat, we used a handheld Global Positioning System to record the location and marked it with a flag. We sectioned off one-third of the sample and collected it in a plastic bag by inverting the bag to prevent contamination. We left the remaining sample in the field as found, except that when a scat was deposited on the travel portion of a road, we transferred the remaining sample to a nearby flat stone. On day 5 and day 10 post-deposition, we revisited each scat and collected an additional one-third in a similar manner as day 1 . We randomly assigned an age treatment to each one-third scat sample.

We processed all samples on the day of collection. We used a razor blade to scrape shavings from the surface of each sample. We mixed the shavings to ensure randomization, divided them into 3 equal portions, and transferred them to 2.0-mL microcentrifuge tubes containing a preservative in an approximately 1:4 volume scat to solution ratio. This method allowed for each scat sample to be subjected to 3 age treatments and for the 3 age treatments to be preserved in each of 3 preservative treatments (DET buffer, EtOH, and lysis buffer). This strategy had the benefit of blocking out differences in amplification and reliability due to intrinsic differences among scat samples relative to DNA quality. We also obtained tissue samples from 17 coyotes from our study site (12 individuals were trapped and released, and 5 were obtained during United States Department of Agriculture control operations) to aid in the selection of microsatellite markers and for use as references for species verification. We stored tissue samples in $5 \mathrm{~mL}$ of lysis buffer. Animal capture protocols were approved by Texas Tech University's Institutional Animal Care and Use Committee (protocol no. 06023-06).

We analyzed scat samples for dietary content prior to genetic analyses. We categorized prey remains as mammalian, insect, juniper berry, or other. We selected scat samples for subsequent genetic analyses based on monotypic composition (i.e., comprised entirely of 1 known food type), except that we relaxed this criterion for scats comprised of insects due to infrequency of occurrence of scats comprised of $100 \%$ insect remains and the rarity of complete treatment representation (i.e., scats comprised of insect remains degraded more quickly than those of other dietary components, which often precluded second and third collections).

\section{DNA Extraction, Mitochondrial DNA Amplification, and Species Verification}

We performed fecal DNA extractions in a separate laboratory from PCRs in a room free of concentrated canid DNA or $\mathrm{PCR}$ product. We used aerosol-resistant filter tips in fecal
DNA extractions and $\mathrm{PCR}$ procedures and included negative controls in each fecal DNA extraction and PCR to monitor for contamination. All genetic analyses were performed by one person so that laboratory techniques and allele scoring was consistent.

Scat samples remained in storage buffer at room temperature for approximately 1 year prior to DNA extraction with the QIAamp DNA Stool Mini-kit (Qiagen Genomics, Valencia, CA). We first centrifuged EtOH and DET preserved samples for $10 \mathrm{~min}$ and discarded the preservation buffer. We homogenized lysis-preserved samples by vortexing and then transferred $350 \mu \mathrm{L}$ of solution to a new $2-\mathrm{mL}$ tube, taking care not to transfer solid fecal material. We chose the QIAamp DNA Stool Mini-kit because it was the most commonly employed fecal DNA extraction technique to date (Waits and Paetkau 2005). We extracted tissue samples using the QIAmp tissue kit (Qiagen Genomics) or the PureGene isolation kit (Gentra Systems, Minneapolis, MN).

To limit microsatellite amplification to coyote fecal samples containing sufficient quantities of amplifiable host DNA, we initially amplified extracts from samples collected on day 1 at a 200-base pair fragment of the mitochondrial DNA (mtDNA) control region using primers ScatSeqF and ScatSeqR (Adams et al. 2003). We amplified the control region in $12.5-\mu \mathrm{L}$ reactions containing $2.5 \mu \mathrm{L}$ of DNA, $6.56 \mu \mathrm{L}$ of double-deionized $\mathrm{H}_{2} \mathrm{O}, 0.5 \mu \mathrm{L}$ of bovine serum albumin (BSA, $10 \mathrm{mg} / \mathrm{mL}$ ), $0.13 \mu \mathrm{L}$ forward and reverse primers $(10 \mu \mathrm{M}$ each), $2.5 \mu \mathrm{L}$ of buffer $(0.3 \mathrm{M}$ Tris, $0.0175 \mathrm{M} \mathrm{MgCl}_{2}, 0.075 \mathrm{M}$ ammonium sulfate at $\mathrm{pH}$ 8.5), $0.13 \mu \mathrm{L}$ of dNTPs $(10 \mathrm{mM})$, and $0.06 \mu \mathrm{L}(1.25 \mathrm{U})$ of Promega Buffer B Taq polymerase (Promega Corporation, Fitchburg, WI) with the profile described in Adams et al. (2003). We cycle sequenced all samples using the BigDye Terminator v3.1 Cycle Sequencing kit (Applied Biosystems, Foster City, CA) and analyzed them on an ABI 3100 Avant automated sequencer (Applied Biosystems). We analyzed sequences using SEQUENCHER 4.7 (Gene Codes Corporation, Inc., Ann Arbor, MI).

We determined species of origin by comparing fecal sample sequences to reference sequences generated from tissue samples of 17 coyotes and 2 gray foxes (Urocyon cinereoargenteus) collected on our study site, and sequences obtained from GenBank (National Center for Biotechnology Information, 2009). We used only samples that successfully yielded coyote mtDNA control region sequences for microsatellite analyses.

\section{Microsatellite Analyses and Quantification of Genotyping Error Rates}

Using fluorescent-dye labeled forward primers, we amplified 6 loci (all tetranucleotides; FH2001, FH2054, FH2088, FH2096, FH2161, CXX2235; Francisco et al. 1996, Breen et al. 2001) in 23 -allele multiplex PCRs (FH2001, FH2096, and FH2161 in one PCR; FH2054, FH2088, and CXX2235 in the other) after optimizing relative primer concentrations. We amplified microsatellite loci in $10-\mu \mathrm{L}$ reactions containing $3.0 \mu \mathrm{L}$ DNA, $0.6 \mu \mathrm{L}$ doubledeionized $\mathrm{H}_{2} \mathrm{O}, 0.4 \mu \mathrm{L}$ BSA $(10 \mathrm{mg} / \mathrm{mL}), 1 \mu \mathrm{L}$ primer 
mix, and $5 \mu \mathrm{L}$ Qiagen Multiplex PCR Master Mix (Qiagen Genomics). We used the following touchdown profile for both multiplex reactions: initial denaturation at $95^{\circ} \mathrm{C}$ for $15 \mathrm{~min} ; 12$ cycles of $94^{\circ} \mathrm{C}$ for $30 \mathrm{~s}, 60^{\circ} \mathrm{C}$ for $90 \mathrm{~s}$ (dropping by $0.5^{\circ} \mathrm{C}$ per cycle), $72^{\circ} \mathrm{C}$ for $60 \mathrm{~s} ; 33$ cycles of $89^{\circ} \mathrm{C}$ for $30 \mathrm{~s}, 55^{\circ} \mathrm{C}$ for $90 \mathrm{~s}, 72^{\circ} \mathrm{C}$ for $60 \mathrm{~s}$; final extension of $60^{\circ} \mathrm{C}$ for $30 \mathrm{~min}$. We ran products on an ABI 3100 Avant automated sequencer using GS-400HD ROX size standard (Applied Biosystems). We analyzed gels using GENEMAPPER 3.0 software (Applied Biosystems).

We generated microsatellite genotypes from fecal extracts using the comparative multiple tubes approach (Frantz et al. 2003), a data replication method used to minimize error in consensus genotypes. According to the protocol, we initially amplified all loci twice. If a locus indicated the same heterozygous genotype for the initial amplifications, we accepted it without further replication. Otherwise, we replicated PCRs until we observed each genotype at least twice, except that homozygous genotypes required $\geq 3$ observations for acceptance. We conducted $\leq 5$ replications at each locus.

We determined genotyping error rates by quantifying mismatches among replicate PCRs while generating consensus genotypes. We established a consensus genotype (and thus a reference genotype) for each scat sample $(n=20)$ by comparing all treatment genotypes of the respective sample. Our study design allowed us to compare up to 9 consensus treatment genotypes obtained from the same scat sample. We required $\geq 2$ matching consensus treatment genotypes before we accepted a sample consensus. We first analyzed 1-day-old treatments, followed by 5-day-old, and finally 10-day-old treatments. We only considered the latter when establishing the consensus genotype if the band quality (e.g., peak intensity and clarity) was sufficient. Once we established consensus sample genotypes, we quantified errors by comparing treatment genotypes to the consensus sample genotype. We categorized genotyping errors as $\mathrm{ADO}$ or FA. We evaluated errors only for loci from which we could establish the sample consensus genotype. We calculated mean $\mathrm{ADO}$ and FA rates across loci using Broquet and Petit (2004: equations 2 and 4). We calculated failed amplification rates across loci as the number of unsuccessful PCRs (i.e., based on the absence of PCR products of the expected size) divided by the total number of attempted PCRs. When diet was included, we also computed the mean number of replications conducted per locus for treatments in which consensus genotypes successfully matched the sample consensus genotype.

We analyzed 4 dependent variables: 1) ADO rate, 2) FA rate, 3) failed amplification rate, and 4) mean number of replications required to reach the correct consensus genotype. We used a generalized linear mixed model (McCulloch et al. 2008) for the first 3 variables and a general linear mixed model (McCulloch et al. 2008) for the latter variable. We considered variation from scat to scat as nuisance variation. Thus, the experimental design of our study fit a randomized block design with a split-plot arrangement. The block was each individual scat sample discovered during surveys. We first attempted to quantify genotyping reliability irrespective of diet content. In these analyses, the treatment effects were preservation method (DET buffer, lysis buffer, and EtOH) and sample age ( 1 day, 5 days, and 10 days old). Given the randomization, collection age was a main plot treatment and buffer was a subplot treatment. In this model, we considered the scat sample a random effect and age and buffer as fixed effects; we modeled a first-order autoregressive variancecovariance structure to account for repeated measures. In our analyses of the influence of diet, we included diet content (mammal, insect, and juniper remains), preservation method (DET buffer and EtOH only), and sample age (1 day and 5 days old only) as treatment effects. We excluded samples stored in lysis buffer because they performed poorly (see Results Section). Similarly, we did not include samples collected on day 10 in the analyses of dietary effects. Again, we considered the scat sample a random effect and diet content and buffer as fixed effects; the inclusion of content in the model followed Kempthorne (1952) and Littell et al. (1996). For all analyses, we considered variation among loci residual variation. When an interaction between factors was significant, we interpreted simple main effects and simple effects (Kirk, 1995). We used a protected least significant differences analysis to separate means followed by a significant $F$-test, using Satterthwaite's degrees of freedom. We used SAS 9.2 (SAS Institute, Cary, NC) for statistical analyses.

\section{RESULTS}

We extracted and attempted amplification from 34 scats before reaching our target of 20 scats from which the mtDNA control region fragment could be successfully amplified and determined to be of coyote origin. Of these, 4 failed to amplify ( $88 \%$ success) and 10 were of gray fox origin.

\section{Evaluation of Sample Age and Preservation Buffers}

We established a consensus sample genotype for 111 of 120 sample-loci (20 samples $\times 6$ loci; we could not establish 6 loci from one sample and 3 from 2 others). Including all treatment combinations (up to 9) for all 6 loci, the correct consensus genotype was generated at 524 of 1,026 (51.1\%) loci attempts.

The type of preservation buffer had an effect on the rate of $\mathrm{ADO}\left(F_{2,94.43}=19.17, P \leq 0.001\right), \mathrm{FA}\left(F_{2,92.1}=15.59\right.$, $P \leq 0.001)$, and failed amplifications $\left(F_{2,132.7}=10.22\right.$, $P \leq 0.001$; Fig. 1). Scats stored in DET buffer and EtOH yielded fewer FA, fewer ADO, and fewer instances of failed amplifications than samples stored in lysis buffer for all 3-sample ages. Although DET buffer yielded lower mean error rates than EtOH (ADO: 0.15 vs. 0.27; FA: 0.20 vs. 0.28$)$, these differences were not significant (ADO: $t_{98.67}=-1.88, P=0.064 ; \mathrm{FA}: t_{97.88}=-1.33$, $P=0.185)$. Failed amplification rates for both DET and EtOH were similar (0.07).

As scat samples aged, we found increasing rates of $\mathrm{ADO}\left(F_{2,31.04}=6.51, P=0.004\right), \mathrm{FA}\left(F_{2,30.38}=7.05\right.$, $P=0.003)$, and failed amplifications $\left(F_{2,133.4}=3.84\right.$, $P=0.024 ;$ Fig. 1). From day 1 to day 10, we observed rates of ADO increase from 0.19 to 0.49 or approximately $158 \%$, 
a

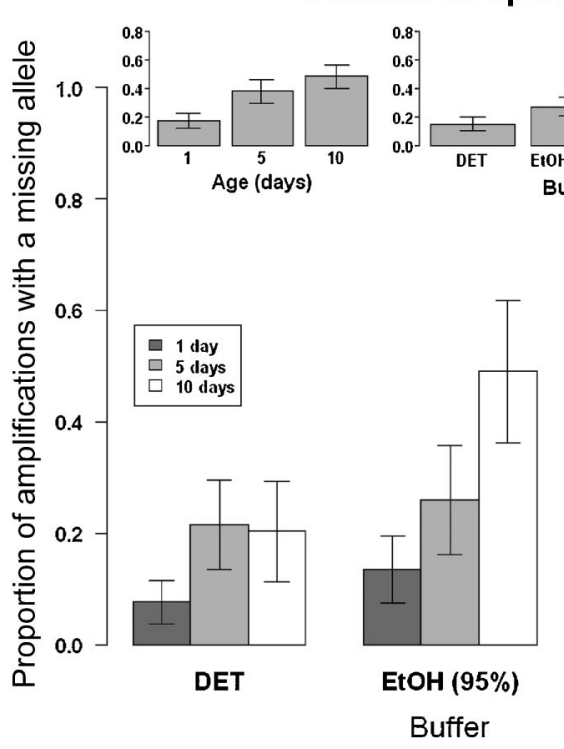

b

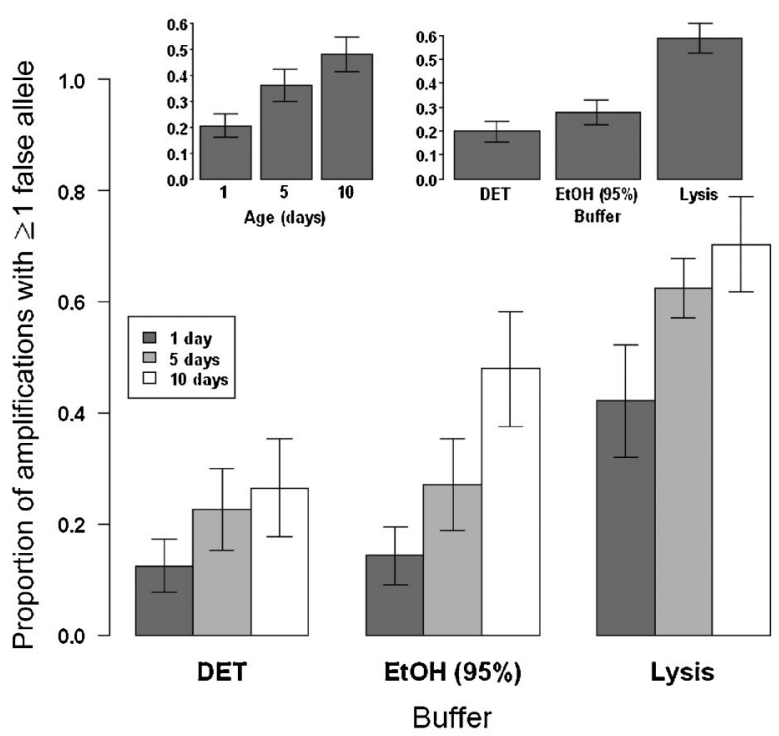

C

Failed amplifications

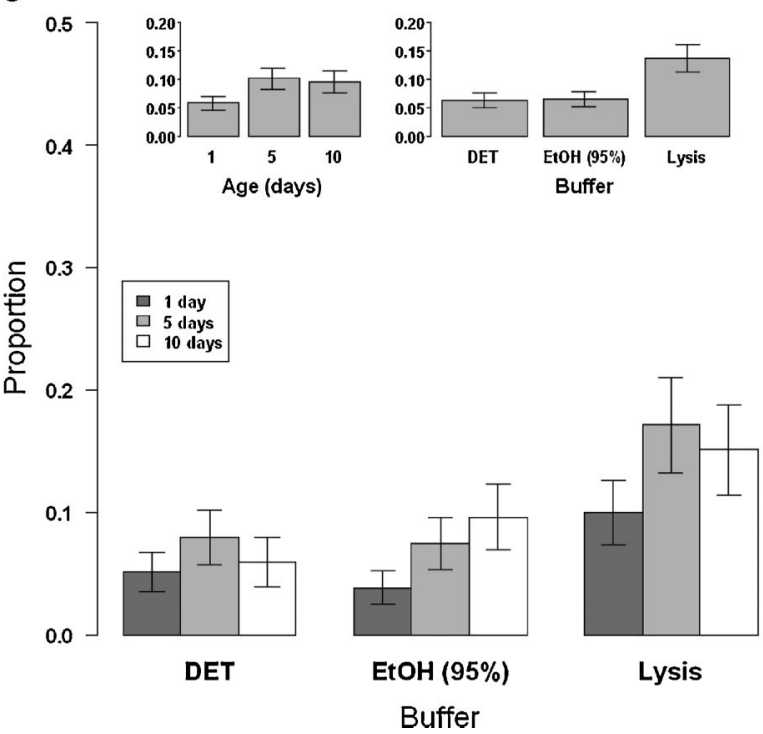

Figure 1. Rates of (a) allelic dropout, (b) false alleles, and (c) failed amplifications of 6 microsatellite loci amplified from DNA extracted from coyote scats collected in Catron County, New Mexico, USA in June-September 2007. We collected scats 1 day, 5 days, and 10 days after deposition and stored in DET buffer, $\mathrm{EtOH}$, and lysis buffer. Imbedded bar graphs show mean proportions across the 3 age treatments and the 3 buffer treatments. We obtained data by attempting to generate consensus genotypes according to the multiple tubes approach and counting mismatches among replicate polymerase chain reactions. We generated genotypes from 20 samples at 6 loci with up to 9 treatments $(n=1,026)$. For each treatment effect, we show the mean and its standard error.

FA increase from 0.20 to 0.48 or approximately $140 \%$, and failed amplifications increase from 0.06 to 0.10 or approximately $67 \%$. Quality of DNA did not decline at a constant rate among the 3 ages. Mean error rates for samples collected on day 1 were different from day 5 (ADO: $t_{31.24}=-2.54$, $P=0.016$; FA: $t_{30.84}=-2.33, P=0.026$; failed amplifications: $\left.t_{142.9}=-2.60, P=0.01\right)$, but measures between day 5 and day 10 were not different (ADO: $t_{29.69}=-1.05$, $P=0.303$; FA: $t_{29.06}=-1.45, P=0.157$; failed amplifications: $\left.t_{117.4}=-0.27, P=0.784\right)$. Relative to day 1 samples, 5-day-old samples showed an increase in ADO, FA, and failed amplifications of approximately $111 \%$ (0.18 vs. $0.38), 71 \%$ ( 0.21 vs. 0.36 ), and $83 \%$ (0.06 vs. 0.11 ), respectively. We found no interaction effects between sample age and buffer (ADO: $F_{4,93.55}=0.33, \quad P=0.854 ; \quad$ FA: $F_{4,91.58}=0.3, \quad P=0.877 ; \quad$ failed amplifications: $\left.F_{4,127.4}=0.54, P=0.717\right)$.

\section{Effects of Dietary Content}

Nine scat samples were comprised of $100 \%$ mammalian prey remains, 5 were comprised of $\geq 95 \%$ insect remains, and 6 were comprised of $100 \%$ juniper remains. We used these scats to evaluate the influence of diet content on microsatellite genotyping relative to storage buffer and sample age.

Frequency of $\mathrm{ADO}(n=372)$ did not differ among diets $\left(F_{2,31.87}=0.40, P=0.673\right)$ and there was no interaction effect for diet content $\times$ sample age $\left(F_{2,31.91}=0.37\right.$, $P=0.694), \quad$ diet $\quad$ content $\times$ buffer $\quad\left(F_{2,33.49}=2.47\right.$, 
$P=0.1)$, or diet content $\times$ sample age $\times$ buffer $\left(F_{2,33.53}=0.73, \quad P=0.489\right)$. Regarding $\mathrm{FA}$ rates $(n=443)$, we found a strong interaction between diet content $\times$ buffer $\left(F_{2,32.75}=10.64, P \leq 0.001\right.$; Fig. 2$)$ signifying that the optimal preservation technique depended on the food remains comprising the scat. Juniper-predominant (JR) scats preserved in DET buffer yielded fewer FA than those preserved in $\mathrm{EtOH}\left(t_{49.31}=-3.88, P \leq 0.001\right)$ and conversely, mammal-predominant (MR) scats stored in EtOH produced fewer FA than those preserved in DET buffer $\left(t_{29.47}=2.45, P=0.02\right)$. Rates of $\mathrm{FA}$ did not differ between insect-predominant (IR) scats stored in DET buffer and $\operatorname{EtOH}\left(t_{24.13}=0.48, P=0.634\right)$. No other factors influenced FA rates (diet content: $F_{2,31.06}=0.42$, $P=0.660$; diet content $\times$ sample age: $F_{2,30.35}=0.41$, $P=0.667$; diet content $\times$ sample age $\times$ buffer: $F_{2,32.32}=1.14, P=0.332$ ). Considering scats preserved in DET buffer, JR scats yielded fewer instances of FA than did MR and IR scats $\left(t_{78.49}=-2.81, P=0.006\right.$, $t_{66.8}=2.38, P=0.02$, respectively), whereas $\mathrm{MR}$ and IR yielded similar FA rates $\left(t_{41.84}=-0.05, P=0.959\right)$. Samples stored in EtOH also varied in FA rates dependent on prey composition. Mammal-predominant scats generated less FA than did JR scats $\left(t_{45.2}=2.52, P=0.015\right)$. Although $\mathrm{EtOH}$-stored MR scats exhibited lower FA rates than did EtOH-stored IR scats $(11.1 \%$ vs. $21.5 \%$, respectively), this difference was not significant $\left(t_{50.28}=1.04\right.$, $P=0.305)$. We found no difference among IR and JR scats preserved in $\mathrm{EtOH}\left(t_{43.95}=-1.02, P=0.312\right)$. Analysis of failed amplification rates failed to converge, which precludes reporting of these results.

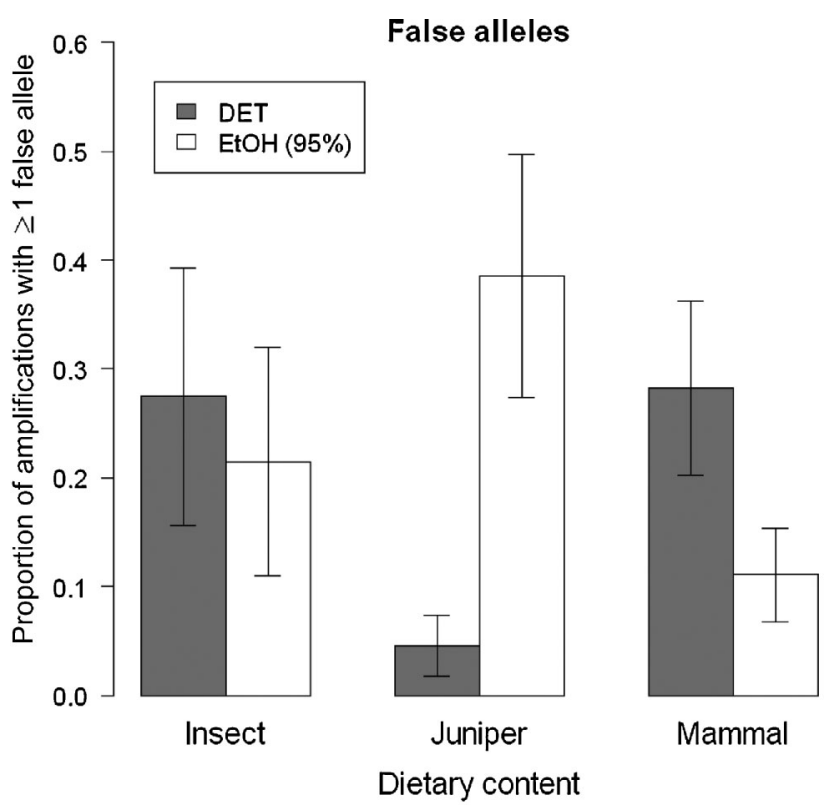

Figure 2. Effect of diet content and storage buffer on false allele rates for 6 microsatellite loci amplified from coyote fecal DNA collected in Catron County, New Mexico, USA in June-September 2007. We included only samples collected 1 day and 5 days post-deposition and scats stored in DET buffer and ethanol (EtOH) due to poor reliability of other treatments. For each treatment effect, we show the mean proportion and standard error.
We further quantified treatment effects on genotyping reliability by comparing mean number of replicates per locus for correctly genotyped treatment loci. Results indicated that diet content had an effect $\left(F_{2,22.7}=4.80, P=0.018\right)$ but sample age did not $\left(F_{1,23}=0.31, P=0.583\right)$. Mammalpredominant and JR scats required, on average, the fewest replications to reach the correct consensus genotype with $2.44(\mathrm{SE}=0.08)$ and $2.5(\mathrm{SE}=0.10)$ replicates, respectively, a difference that was not significant $\left(t_{23.2}=0.47\right.$, $P=0.643)$. Insect-predominant scats required an average of $2.9(\mathrm{SE}=0.13)$ replications, more than both $\mathrm{MR}$ scats $\left(t_{22.3}=3.04, P=0.006\right)$ and $\mathrm{JR}$ scats $\left(t_{22.4}=2.42\right.$, $P=0.024)$.

\section{DISCUSSION}

Our study is the first to use scats of wild, free-ranging animals to analyze the effects of preservation method, age of scat, and diet on microsatellite genotype reliability. We found that all 3 factors impacted microsatellite genotyping of canid fecal DNA. Specifically, we found that both DET buffer and $\mathrm{EtOH}$ were far superior to lysis buffer, suggesting the lysis buffer protocols we employed should not be used for preserving fecal material for subsequent DNA analyses. Counter to our findings, Santini et al. (2007) suggested that lysis buffers should perform as well as EtOH. Disparities between results may be due to a variety of factors, including differences in tissue lysis buffer composition and varying protocols used to preserve, extract, or PCR amplify fecal DNA. For example, as lysis buffer is sensitive to tissue overloading, lysis preservation may have been compromised in our study due to an excessive feces to buffer ratio.

Our results also indicate that DET buffer and EtOH preservation yielded equally reliable genotypes when we did not consider diet content. Frantzen et al. (1998) found DET buffer to be superior to $70 \% \mathrm{EtOH}$ in preserving baboon (Papio cynocephalus) feces. Murphy et al. (2002) however, suggested use of $90 \% \mathrm{EtOH}$ rather than DET buffer because of higher amplification success rates, but the authors found no difference between the 2 preservatives in error rates. Frantz et al. (2003) reported no difference in amplification success between DET buffer and 70\% EtOH for preserving European badger (Meles meles) fecal DNA. Discrepancies among studies may be due to varying concentrations of $\mathrm{EtOH}$, varying time in storage buffer, different extraction methods, environmental-related influences, or dietary differences among animal subjects.

Similar to other findings (i.e., Lucchini et al. 2002, Piggott 2004, Santini et al. 2007), we found that as the number of days between scat deposition and collection increased, average frequency of errors and failed reactions also increased. Our results indicated that DNA extracted from 1-day-old samples were superior to both 5-day-old and 10-day-old samples (although in some cases, 5-day-old and 10-dayold samples were equally as reliable as 1-day-old samples) and more interestingly, that 5-day-old samples and 10-dayold samples were equally reliable. These results indicate that the relationship between DNA degradation rate and sample age is not linear, at least at the scale we measured, and that 
greater rates of degradation occur in the first 5 days relative to days 6-10. However, our study lacked adequate resolution to model actual rates of change from day to day. Thus, we could not determine the nature of the relationship between degradation rate and age (e.g., linear, exponential decay) within the first 5 days.

We concluded that samples should be collected within 5 days of deposition to yield the highest DNA quality and quantity. Piggott (2004) and Santini et al. (2007) also used scats of known age to compare PCR results from fecal DNA of various ages. Piggott (2004) found that amplification success declined and error rates increased beyond 1 week of age, whereas Santini et al. (2007) suggested that gray wolf (Canis lupus) scats should be collected within 1 week of deposition and found significant declines in PCR success as early as 3 days post-deposition. Although collecting scats 1 day post-deposition is likely unrealistic for most studies, samples of this age yield the highest quality fecal DNA and therefore, served as a standard for comparison in our study.

Perhaps most significantly, our analyses involving dietary content revealed that the best preservation method may depend on the dietary remains comprising the scat. We found that relative to FA rates, DET buffer preserved JR samples much more efficiently than did $\mathrm{EtOH}$. This pattern was opposite for $\mathrm{MR}$ samples, as $\mathrm{EtOH}$ preservation led to lower FA rates than DET buffer. We found no differences between the preservatives DET buffer and EtOH for IR samples. For scats preserved in DET buffer, JR samples were more reliably genotyped than both IR and MR samples. For those preserved in EtOH, MR samples yielded fewer FA than JR. However this interaction between diet content and storage buffer did not emerge in our analyses of ADO or mean number of replications, perhaps because of different processes generating $\mathrm{ADO}$ versus $\mathrm{FA}$ errors or because of a limited sample size of successfully genotyped loci given high levels of variation both within and among samples. Our results suggest that scats composed primarily of insect remains will require more replicates to reach the consensus genotype than MR or JR scats, but the number of JR and MR replicates will be equivalent.

We do not know if the pattern we report for FA rates from DNA extracted from scats containing juniper berries extends to scats containing other plant-derived food items or if there are certain chemical compounds within juniper berries that interfere with $\mathrm{EtOH}$ (or facilitate DET buffer) preservation. Evidence from a captive brown bear study suggested amplification rates did not differ between plant and mammal diets, although FA rates were not quantified (Murphy et al. 2003).

The causative mechanism for the interaction effect between diet content and optimal preservative is unknown, but we surmise that the primary influence is due to chemical properties of juniper berries and their reaction with the fecal material and the preservation buffer. Secondary plant compounds such as phenolics and polysaccharides have made the extraction of high quality DNA from plants or plant products containing high concentrations of these compounds-such as conifers and fruits-difficult, perhaps by binding to DNA molecules during the storage or extraction process (Kim et al.
1997). Kim et al. (1997) report increased efficiency of high quality DNA isolation from several plant tissues, including leaves of Chinese juniper (Juniperus chinensis) and various cultivated fruits, by (among other steps) incubating tissue (ground in 1\% 2-mercaptoethanol) in extraction buffer containing Tris- $\mathrm{HCl}, \mathrm{EDTA}$, and $\mathrm{NaCl}$. These 3 chemical compounds are also components of DET buffer, which may help to explain the superior efficiency of DET buffer at preserving scats composed of juniper berries. However there are likely other factors involved as well.

We predict that our findings relative to the influence of preservation technique and diet on genotyping success will be consistent for other taxa and in other regions. Due to the sensitivity of fecal DNA to environmental conditions, however, degradation rates will of course depend upon weatherrelated variables, and our results may not hold if samples are collected in climates different from ours. Scats exposed to high ambient temperatures will yield poorer quality DNA than scats exposed to cooler temperatures (Nsubuga et al. 2004). Some of the highest genotyping success rates have been reported in climates where scats generally freeze upon defecation (e.g., Prugh et al. 2005). Also, empirical data suggested that dry conditions during scat exposure are more conducive to fecal DNA amplification relative to humid conditions (Farrell et al. 2000, Piggott 2004). For example, Farrell et al. (2000) report successful mtDNA sequencing from $66 \%$ of scats collected from western Venezuela during the dry season, compared to only $28 \%$ collected in the wet season.

Error rates we reported are higher than many of those reported in the literature. However, the relevance of our reported error rates is not as error rates per se, but as relative error rates among our treatments. As Broquet and Petit (2004) explained, error rates should not be compared across studies due to variation in methodology used for their generation and, at least for FA, because quantification is dependent on the recorder. We consistently used liberal criteria for scoring alleles, which would inflate the incidence of FA relative to more conservative methods. Also, studies reporting error rates typically use only data from samples from which a consensus genotype was generated at a particular locus or at a particular proportion of attempted loci (e.g., Murphy et al. 2002, Frantz et al. 2003, Prugh et al. 2005), which underestimates the true incidence of errors. Because we were able to deduce consensus genotypes from other subsamples of the same feces, we were able to utilize these erroneous loci where others could not. Furthermore, pervasive or sporadic contamination can be avoided or detected in most cases by negative controls (Broquet and Petit 2004), and studies requiring an accurate (or conservative) number of individuals or genotypes must discard samples showing contamination (e.g., Prugh et al. 2005). We did not have this problem because our objectives were to evaluate relative success and reliability of genotypes among treatments. Instances of undetected contamination would not be expected to influence any particular treatments more than others as long as allele scoring was consistent. Therefore, under the assumption that contaminant-caused error would 
be randomly distributed across loci, there should not have been systematic bias in our results.

Another potential factor that may have influenced our results was nonuniform distribution of intestinal cells in feces (Kohn and Wayne 1997) and could explain some discrepancies between patterns we observed for FA rates and average number of replications to consensus. Other authors have avoided this problem by homogenizing the sample prior to removing material for extraction (e.g. Wasser et al. 1997, Murphy et al. 2002), but this approach was not possible given our study design, namely the need to divide samples into 3 age treatments.

\section{MANAGEMENT IMPLICATIONS}

Understanding the influence of sample age, storage buffer, and dietary remains on genotyping success is important. For example, for species with highly varied diets across habitats, geographical areas, or seasons such as coyotes (Camenzind 1978, Harrison and Harrison 1984), the optimal preservation method for preserving fecal DNA may depend upon the primary food source of the population during sampling, and sample age will give a good indication of how much effort will be required in the lab. Scat samples collected at 5 days and 10 days post-deposition yielded DNA that is less reliable than samples collected at 1 day of age, confirming that frequent sampling is important for the collection of samples yielding the highest quality and quantity DNA. Sampling scats $\leq 1$ day post-deposition is unrealistic for most studies, but our data suggest that DNA can consistently be extracted from scats beyond 1 day of exposure, albeit with field and lab costs that will increase with sample age due to the increased number of samples necessary for collection and extraction and also greater numbers of PCR replications required for accurate genotyping.

Our preservation experiments in which diet content was not considered revealed that DET buffer and $\mathrm{EtOH}$ performed equally well in preserving fecal DNA, and that our protocols using lysis buffer should not be used for fecal DNA preservation. Complicating the matter, there appears to be an interaction between preservative and dietary content, signifying that the optimal buffer may actually depend on the diet of the subjects being studied. Judging from our FA analyses, if sampling scats of animals primarily feeding on insects, either DET buffer or EtOH can be expected to yield DNA of equivalent quality. If study individuals have a diet comprised of plant-derived food items, such as those of herbivore, granivore, and frugivore species, we suggest that DET buffer should be chosen. Finally, EtOH should be employed for scats of obligate carnivores and for facultative carnivore populations subsisting predominantly on mammalian prey as is often the case for particular areas and seasons. Selecting the optimal preservation technique for facultative carnivores with mixed diets (i.e., plant- and mammal-derived food sources) may not be so simple, and we recommend that a pilot study be conducted to test the efficiency of EtOH and DET buffer preservation of scats of mixed remains. Our methods did not consider scats of mixed content, and we cannot rule out a possible interaction effect between multiple prey remains on DNA extraction or amplification. Additional research is needed to determine how other plant-derived food items such as fruits and berries influence fecal DNA extraction and amplification, and how scats composed of mixed-diet remains compare to our findings.

Our results are likely applicable for all canid species, as well as noncanid carnivores. Given the sensitivity of DNA to environmental exposure, climatic conditions are likely more important than taxonomy in influencing microsatellite amplification success and reliability. Our guidelines should aid the development of fecal DNA collection and preservation protocols for research and management efforts employing noninvasive canid fecal DNA techniques.

\section{ACKNOWLEDGMENTS}

Fieldwork and genetic analyses were funded by New Mexico Department of Game and Fish, United States Department of Agriculture-Wildlife Services, Texas Tech University, the California Wolf Center, and the Dr. Donald and Sammie Bricker Foundation. The Houston Safari Club and the Helen DeWitt Jones Foundation funded graduate student scholarships and a graduate fellowship, respectively. We are thankful to the Conservation Genetics Resource Center at the University of California, Los Angeles for valuable suggestions relative to fecal DNA PCR protocols. We also thank L. Prugh for providing fecal sampling suggestions, A. Daugherty for reviewing the manuscript, G. Whetton for access to private property and living accommodations on the Adobe Ranch, the United States Forest Service Beaverhead Work Station crew for office use and accommodations for a field lab, and many graduate students and various technicians that provided lab and field aid, especially J. Weaver, M. McDonough, P. Larsen, and F. Anwarali.

\section{LITERATURE CITED}

Adams, J. R., B. T. Kelly, and L. P. Waits. 2003. Using faecal DNA sampling and GIS to monitor hybridization between red wolves (Canis rufus) and coyotes (Canis latrans). Molecular Ecology 12:2175-2186.

Albaugh, G. P., V. Iyengar, A. Lohani, M. Malayeri, S. Bala, and P. P. Nair. 1992. Isolation of exfoliated colonic epithelial cells, a novel, non-invasive approach to the study of cellular markers. International Journal of Cancer $52: 347-350$

Breen, M., S. Jouquand, C. Renier, C. S. Mellersh, C. Hitte, N. G. Holmes, A. Chéron, N. Suter, F. Vignaux, A. E. Bristow, C. Priat, E. McCann, C. André, S. Boundy, P. Gitsham, R. Thomas, W. L. Bridge, H. F. Spriggs, E. J. Ryder, A. Curson, J. Sampson, E. A. Ostrander, M. M. Binns, and F. Galibert. 2001. Chromosome-specific single-locus FISH probes allow anchorage of an 1800-marker integrated radiation-hybrid/linkage map of the domestic dog genome to all chromosomes. Genome Research 11: 1784-1795.

Broquet, T., N. Menard, and E. Petit. 2007. Noninvasive population genetics: a review of sample source, diet, fragment length and microsatellite motif effects on amplification success and genotyping error rates. Conservation Genetics 8:249-260.

Broquet, T., and E. Petit. 2004. Quantifying genotyping errors in noninvasive population genetics. Molecular Ecology 13:3601-3608.

Camenzind, F. J. 1978. Behavioral ecology of coyotes on the National Elk Refuge, Jackson, Wyoming. Pages 267-294 in M. Bekoff, editor. Coyotes: biology, behavior, and management. Academic Press, New York, New York, USA. 
Cariappa, C. A., W. Ballard, S. Breck, A. J. Piaggio, and M. Neubaum. 2008. Estimating population size of Mexican wolves noninvasively (Arizona). Ecological Restoration 26:14.

Farrell, L. E., J. Roman, and M. E. Sunquist. 2000. Dietary separation of sympatric carnivores identified by molecular analysis of scats. Molecular Ecology 9:1583-1590.

Francisco, L. V., A. A. Langston, C. S. Mellersh, C. L. Neal, and E. A. Ostrander. 1996. A class of highly polymorphic tetranucleotide repeats for canine genetic mapping. Mammalian Genome 7:359-362.

Frantz, A. C., L. C. Pope, P. J. Carpenter, T. J. Roper, G. J. Wilson, R. J. Delahay, and T. Burke. 2003. Reliable microsatellite genotyping of the Eurasian badger (Meles meles) using faecal DNA. Molecular Ecology 12:1649-1661.

Frantzen, M. A. J., J. B. Silk, J. W. H. Ferguson, R. K. Wayne, and M. H. Kohn. 1998. Empirical evaluation of preservation methods for faecal DNA. Molecular Ecology 7:1423-1428.

Gagneux, P., C. Boesch, and D. S. Woodruff. 1997. Microsatellite scoring errors associated with noninvasive genotyping based on nuclear DNA amplified from shed hair. Molecular Ecology 6:861-868.

Goossens, B., L. Chikhi, S. S. Utami, J. de Ruiter, and M. W. Bruford. 2000. A multi-sample, multi-extracts approach for microsatellite analysis of faecal samples in an arboreal ape. Conservation Genetics 1:157-162.

Harrison, D. J., and J. A. Harrison. 1984. Foods of adult Maine coyotes and their known aged pups. Journal of Wildlife Management 48:922-926.

Kempthorne, O. 1952. The design and analysis of experiments. John Wiley and Sons, New York, New York, USA.

Kim, C. S., C. H. Lee, J. S. Shin, Y. S. Chung, and N. I. Hyung. 1997. A simple and rapid method for isolation of high quality genomic DNA from fruit trees and conifers using PVP. Nucleic Acids Research 25:10851086.

Kirk, R. 1995. Experimental design: procedures for the behavioral sciences. Third edition. Brooks/Cole Publishing Company, Pacific Grove, California, USA.

Kohn, M. H., and R. K. Wayne. 1997. Facts from feces revisited. Trends in Ecology and Evolution 12:223-227.

Littell, R. C., G. A. Milliken, W. W. Stroup, and R. D. Wolfinger. 1996. SAS system for mixed models. SAS Institute, Cary, North Carolina, USA.

Longmire, J. L., M. Maltbie, and R. J. Baker. 1997. Use of "Lysis Buffer" in DNA isolation and its implication for museum collections. Occasional papers, The Museum of Texas Tech University 163: 1-3.

Lucchini, V., E. Fabbri, F. Marucco, S. Ricci, L. Boitani, and E. Randi. 2002. Noninvasive molecular tracking of colonizing wolf (Canis lupus) packs in the western Italian Alps. Molecular Ecology 11:857-868.

McCulloch, C. E., S. R. Searle, and J. M. Neuhaus. 2008. Generalized, linear and mixed models. Wiley, New York, New York, USA.

Monteiro, L., D. Bonnemaison, A. Vekris, K. G. Petry, J. Bonnet, R. Vidal, J. Cabrita, and F. Mégraud. 1997. Complex polysaccharides as PCR inhibitors in feces: Helicobacter pylori model. Journal of Clinical Microbiology 35:995-998.

Morin, P. A., K. E. Chambers, C. Boesch, and L. Vigilant. 2001. Quantitative polymerase chain reaction analysis of DNA from noninvasive samples for accurate microsatellite genotyping of wild chimpanzees (Pan troglodytes verus). Molecular Ecology 10:1835-1844.

Murphy, M. A., L. P. Waits, and K. C. Kendall. 2003. The influence of diet on faecal DNA amplification and sex identification in brown bears (Ursus arctos). Molecular Ecology 12:2261-2265.

Murphy, M. A., L. P. Waits, K. C. Kendall, S. K. Wasser, J. A. Higbee, and R. Bogden. 2002. An evaluation of long-term preservation methods for brown bear (Ursus arctos) faecal DNA samples. Conservation Genetics $3: 435-440$.

National Center for Biotechnology Information [NCBI]. 2009. NCBI home page. <http://www.ncbi.nlm.nih.gov>. Accessed 14 May 2009.

Nsubuga, A. M., M. M. Robbins, A. D. Roeder, P. A. Morin, C. Boesch, and L. Vigilant. 2004. Factors affecting the amount of genomic DNA extracted from ape faeces and the identification of an improved sample storage method. Molecular Ecology 13:2089-2094.

Piggott, M. P. 2004. Effect of sample age and season of collection on the reliability of microsatellite genotyping of faecal DNA. Wildlife Research 31:485-493.

Prugh, L. R., C. E. Ritland, S. M. Arthur, and C. J. Krebs. 2005. Monitoring coyote population dynamics by genotyping faeces. Molecular Ecology 14:1585-1596.

Santini, A., V. Lucchini, E. Fabbri, and E. Randi. 2007. Ageing and environmental factors affect PCR success in wolf (Canis lupus) excremental DNA samples. Molecular Ecology Notes 7:955-961.

Seutin, G., B. N. White, and P. T. Boag. 1991. Preservation of avian blood and tissue samples for DNA analyses. Canadian Journal of Zoology 69: 82-90.

Taberlet, P., S. Griffin, B. Goossens, S. Questiau, V. Manceau, N. Escaravage, L. Waits, and J. Bouvet. 1996. Reliable genotyping of samples with very low DNA quantities using PCR. Nucleic Acids Research 24: 3189-3194.

Taberlet, P., L. P. Waits, and G. Luikart. 1999. Noninvasive genetic sampling: look before you leap. Trends in Ecology \& Evolution 14: 323-327.

Waits, L. P., and D. Paetkau. 2005. Noninvasive genetic sampling tools for wildlife biologists: a review of applications and recommendations for accurate data collection. Journal of Wildlife Management 69:14191433.

Wasser, S. K., C. S. Houston, G. M. Koehler, G. G. Cadd, and S. R. Fain. 1997. Techniques for application of faecal DNA methods to field studies of Ursids. Molecular Ecology 6:1091-1097.

Associate Editor: Emily K. Latch. 